\title{
Intra- and inter-individual chromosome variation in Hoplerythrinus unitaeniatus (Pisces, Erythrinidae). A population from the Brazilian São Francisco river basin
}

\author{
Débora Diniz and Luiz A.C. Bertollo \\ Departamento de Genética e Evolução, Universidade Federal de São Carlos, São Carlos, SP, Brazil.
}

\begin{abstract}
Chromosomal studies were carried out on a population of the fish Hoplerythrinus unitaeniatus (jeju) from Prata river in the São Francisco river basin, Minas Gerais, Brazil using conventional Giemsa staining, C-banding, silver nitrate nucleolar organizer region (Ag-NOR) staining and fluorescent in situ hybridization (FISH) with 18S and 5S rDNA probes. We found a high degree of inter- and intra-individual variability with the identification of $2 n=50,2 n=51$ and $2 n=52$ karyotypes at nearly the same frequency within the population. Intra-individual variation in chromosomal morphology and, consequently, karyotype formulae was also observed, chiefly in the specimens with $2 n=50$ and $2 n=52$ chromosomes. Ag-NORs and 18S rDNA sites also showed numerical and chromosomal variation similar to that found for the $5 \mathrm{~S}$ rDNA sites. Some putative hypotheses are considered in order to explain these results.
\end{abstract}

Key words: karyotypes, C-banding, nucleolar organizing regions, intra- and inter-individual polymorphism.

Received: August 2, 2005; Accepted: November 11, 2005.

\section{Introduction}

Variations in chromosome number and morphology can be found between distinct groups of organisms or different populations of the same species, as well as among different individuals of the same population and even between different cells of the same specimen. Although intra-individual chromosome variation is not a common feature, there are some reports describing its occurrence in fishes. Indeed, different somatic cells of the salmonid Oncorhynchus mykiss ( = Salmo irideus) can show a variation in diploid number from $2 n=58$ to $2 n=65$ with a maintenance of the fundamental number (i.e. the number of chromosome arms) equal to 104, characterizing a Robertsonian polymorphism (Ohno et al.,1965). Similar data have also been reported by Beçak et al. (1966) for Lepomis cyanellus, where three karyotypes were detected within the population: (1) a homozygote form with $2 \mathrm{n}=48$ acrocentric chromosomes, corresponding to the standard karyotype for this species; (2) a homozygote form with $2 n=46$ chromosomes (44 acrocentrics +2 metacentrics); and (3) a heterozygote form with $2 \mathrm{n}=47$ chromosomes (46 acrocentrics +1 metacentric). It was concluded that this variation was due to centric fusions between acrocentric chro-

Send correspondence to Luiz A.C. Bertollo. Departamento de Genética e Evolução, Universidade Federal de São Carlos, Caixa Postal 676, 13565-905 São Carlos, SP, Brazil. E-mail: bertollo@ power.ufscar.br. mosomes, with the consequent formation of the derived metacentric chromosome. The three karyotypes $(2 n=48$, $2 n=47,2 n=46$ ) were observed exclusively in heterozygous specimens and a putative somatic segregation favoring the reconstitution of homozygous cells was proposed to explain the intra-individual polymorphism observed in the heterozygous specimens (Beçak et al., 1966). Other cases of intra-individual chromosome variation have also been observed in O. mykiss and the other salmonids Salmo salar and Salmo trutta (Hartley and Horne, 1984) and in the gobiid Gobius paganellus (Thode et al., 1985, Giles et al., 1985).

In the karyotype of the erythrinid fish Hoplerythrinus unitaeniatus both inter-populational (Giuliano-Caetano et al., 2001; Diniz and Bertollo, 2003) and inter-individual variation (Giuliano-Caetano and Bertollo, 1988) has been reported, indicating high chromosomal diversity in this species.

During the study described in this paper we investigated a $H$. unitaeniatus population from Prata river in the São Francisco river basin, Minas Gerais, Brazil using Giemsa staining, C-banding, silver nitrate nucleolar organizer region (Ag-NOR) staining and fluorescent in situ hybridization (FISH) with $18 \mathrm{~S}$ and $5 \mathrm{~S}$ rDNA probes. We uncovered complex inter- and intra-individual chromosome variation and suggest some hypotheses to explain this situation. 


\section{Material and Methods}

We analyzed 3 male and 11 female Hoplerythrinus unitaeniatus (Agassiz, 1829) from marginal lakes of the Prata river in the São Francisco river basin in João Pinheiro municipality, Minas Gerais state, Brazil.

Metaphase chromosomes were obtained from kidney cells after in vivo treatment with colchicine and conventional air-drying procedures (Bertollo et al., 1978). Active nucleolar organizer regions (NORs) were detected by silver nitrate (Ag-NOR) staining (Howell and Black, 1980) and constitutive heterochromatin by the C-banding method (Sumner, 1972). Fluorescent in situ hybridization (FISH) was performed according to Pinkel et al. (1986). The 18S rDNA probe was obtained from the prochilodontid fish Prochilodus argenteus (Hatanaka and Galetti, 2004) and the 5S rDNA probe from the anostomid fish Leporinus elongatus (Martins and Galetti, 1999). The chromosomes were classified as metacentric (M), submetacentric (SM), subtelocentric (ST) or acrocentric (A) based on their arm ratio (Levan et al., 1964) and organized in decreasing order of size. The metacentric and submetacentric chromosomes were grouped into a single class because the arm ratio values between these two morphological types were quite sim- ilar for several chromosome pairs. The chromosome images were recorded using bright-field microscopy and the CoolSNAP-Pro Software (Media Cybernetic).

\section{Results}

We identified different karyotypes among the specimens, the chromosome number for the 568 metaphases analyzed (Figure 1a) being variable with modal chromosome numbers of $2 n=50$ for 203 metaphases from 2 males and 3 females (Figure 1b), $2 \mathrm{n}=51$ for 187 metaphases from 4 females (Figure 1c) and $2 \mathrm{n}=52$ for 178 metaphases from 1 male and 4 females (Figure 1d).

Besides these differences in diploid number we also found intra-individual variations in chromosome morphology, chiefly in specimens with $2 n=50$ and $2 n=51$, and distinct karyotypes were identified, including some apparently lacking homologues (Figures 2 and 3). Although the specimens bearing $2 \mathrm{n}=52$ chromosomes also presented some variation, it was possible to determine a standard karyotype for this group (Figure 4), as previously reported by Diniz and Bertollo (2003).

The constitutive heterochromatin was located at the pericentromeric region of most of chromosomes and con-
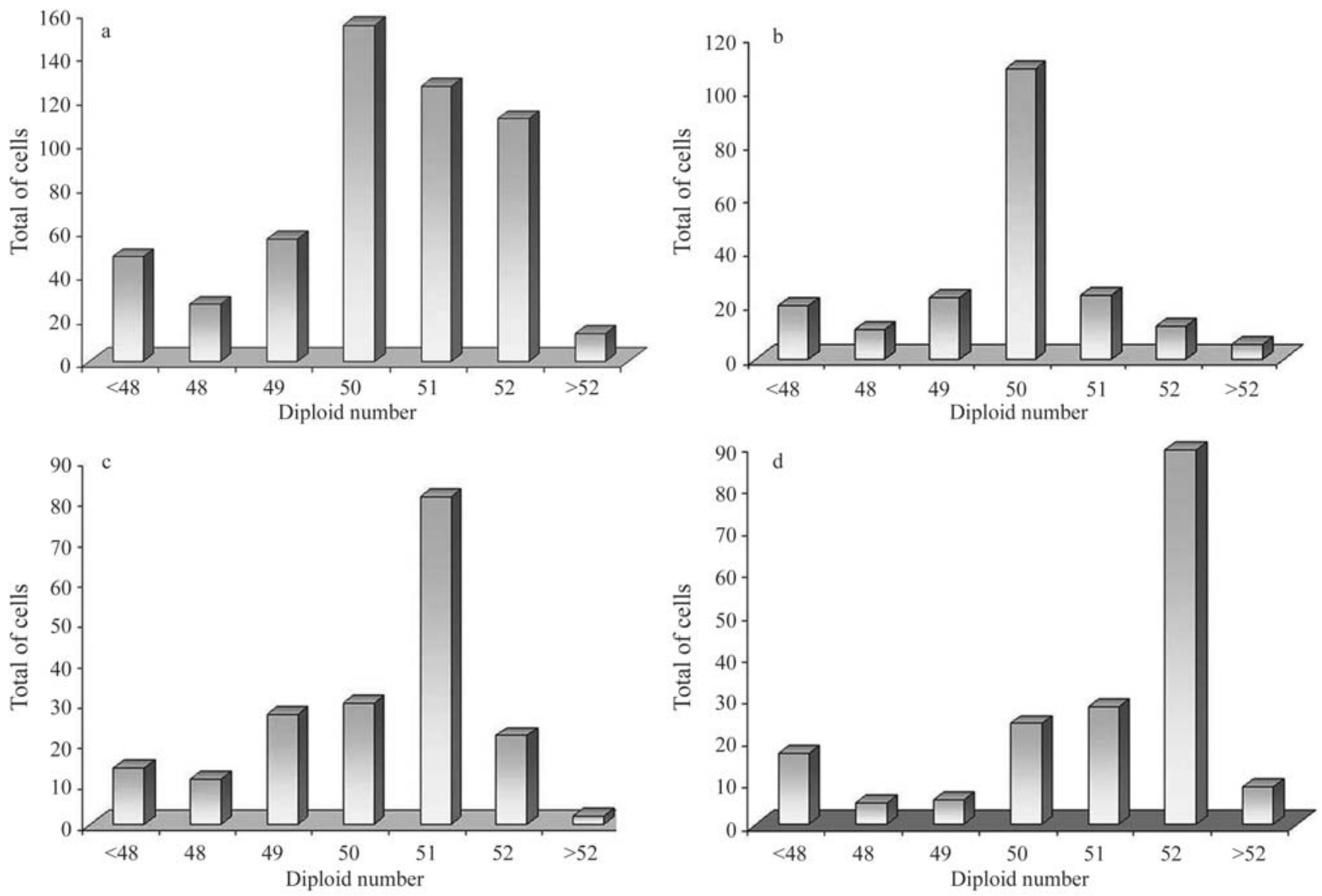

Figure 1 - Frequency of the diploid numbers in the Prata river Hoplerythrinus unitaeniatus population (a) total specimens analyzed; (b) specimens with a $2 \mathrm{n}=50$ modal diploid number (MDN); (c) specimens with a $2 \mathrm{n}=51 \mathrm{MDN}$; (d) specimens with a $2 \mathrm{n}=52 \mathrm{MDN}$. 

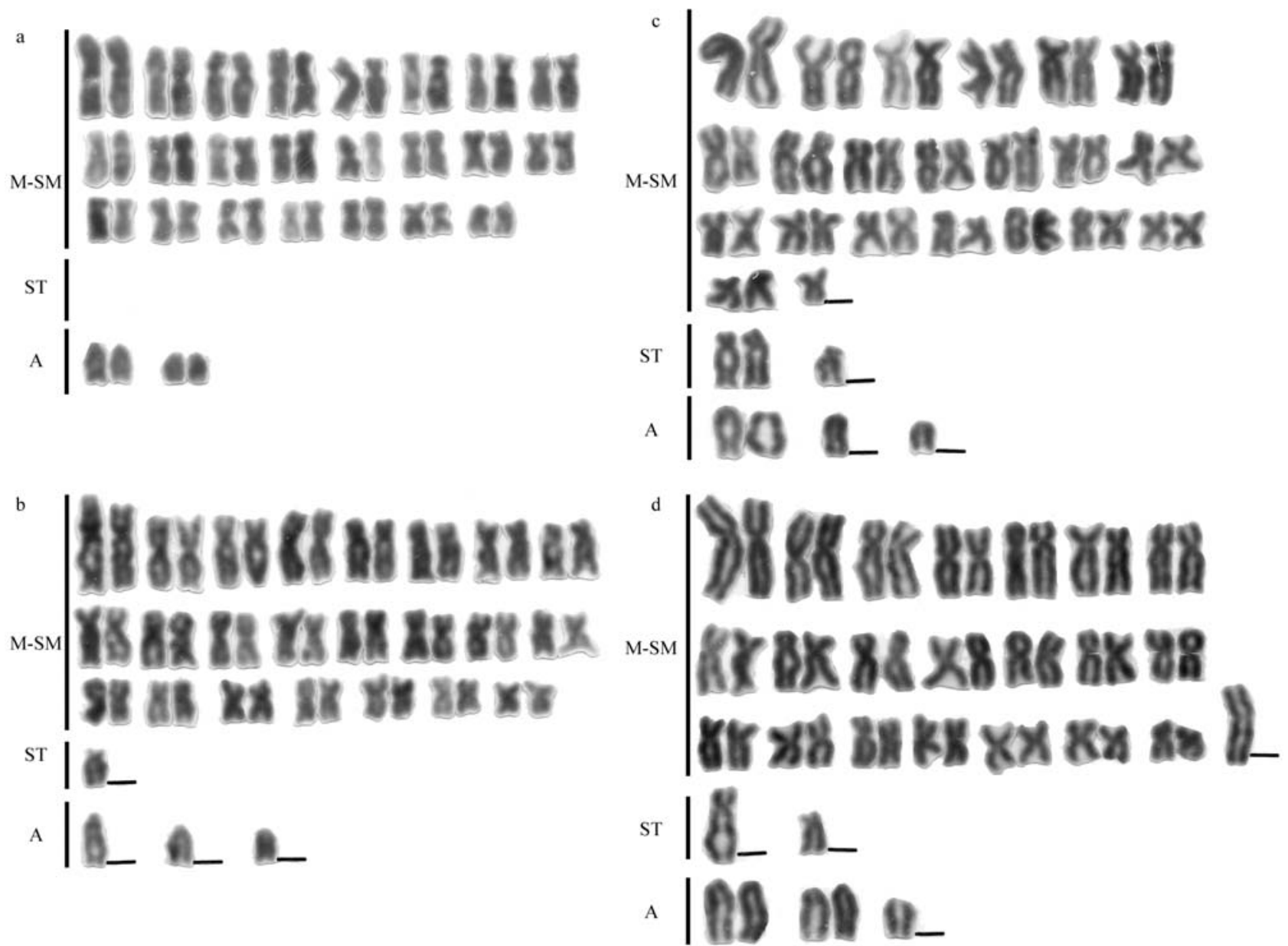

Figure 2 - Karyotypes of Prata river Hoplerythrinus unitaeniatus with $2 \mathrm{n}=50$ chromosomes, showing distinct structures (a-d). The dashes indicate an apparent lacking of homologues.

spicuous interstitial and telomeric C-bands were observed with some pairs (Figure 5). No significant differences in C-banding pattern were observed for the $2 \mathrm{n}=50$ and $2 \mathrm{n}=51$ karyotypes and the previously analyzed $2 \mathrm{n}=52$ karyotype (Diniz and Bertollo, 2003).

A multiple NOR system was constantly observed in the population. Specimens with $2 \mathrm{n}=50$ chromosomes showed telomeric Ag-NORs on the short arm of two apparently non-homologous ST/A chromosomes of distinct sizes and an interstitial site on one $\mathrm{M} / \mathrm{SM}$ chromosome (Figure 6a). Four telomeric Ag-NORs, located on the short arm of two ST/A pairs, were always observed for $2 n=51$ specimens (Figure 6d). The $2 \mathrm{n}=52$ specimens showed 4-6 Ag-NORs, with a prevalence of 4 sites located on the short arm of three ST/A chromosomes and at the interstitial region of one M/SM chromosome (Figure 6g).

Fluorescent in situ hybridization not only supported the Ag-NOR results (Figure 6b, e, h) but detected additional $18 \mathrm{~S}$ rDNA sites in specimens with $2 \mathrm{n}=50$ and $2 \mathrm{n}=52$ chromosomes (Figure 6b, h). However the AgNOR site located on the largest ST/A chromosome of $2 \mathrm{n}=50$ specimens (Figure 6a) was not mapped by FISH.
The 5S rDNA sites were always observed at pericentromeric region of $\mathrm{M} / \mathrm{SM}$ chromosomes in all karyotypes, despite the occurrence of numerical variation amongst them. A modal frequency of two $5 \mathrm{~S}$ rDNA sites was observed in the $2 \mathrm{n}=50$ and $2 \mathrm{n}=51$ karyotypes (Figure $6 \mathrm{c}$, f) while for the $2 n=52$ karyotype a modal frequency of four 5S rDNA sites was detected, two sites on metacentric and two on submetacentric chromosomes (Figure 6i). Sporadic higher numbers of $5 \mathrm{~S}$ rDNA sites in the $2 \mathrm{n}=50$ and $2 \mathrm{n}=51$ karyotypes were located in submetacentric chromosomes.

\section{Discussion}

The Prata river $H$. unitaeniatus population is characterized by complex inter- and intra-individual chromosomal diversity involving both diploid number and karyotype structure. Despite lacking remarkable differences in heterochromatin distribution, the Ag-NORs and $18 \mathrm{~S}$ and $5 \mathrm{~S}$ rDNA sites also reinforce this variability, in view of their variation in number and type of the rDNA-bearing chromosomes. 


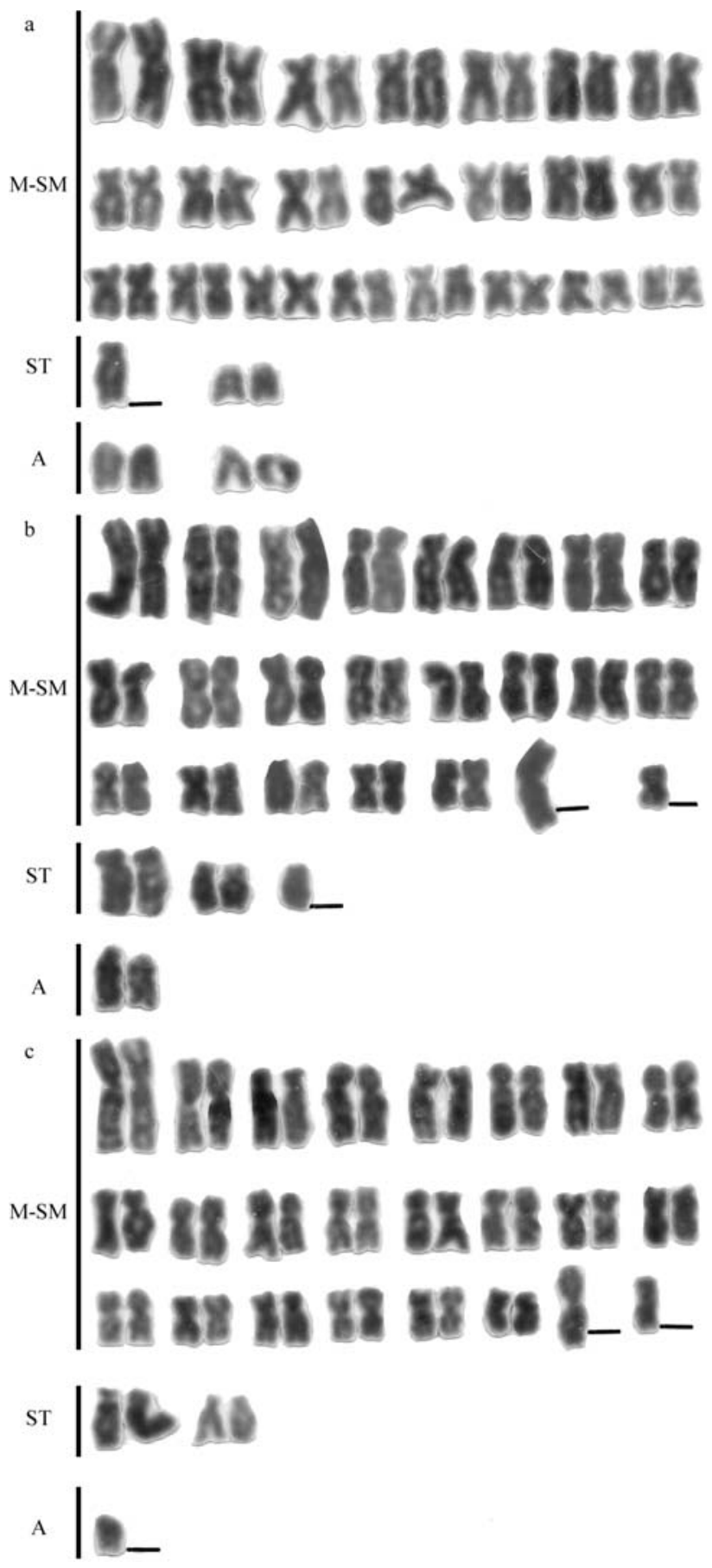

Figure 3 - Karyotypes of Prata river Hoplerythrinus unitaeniatus with $2 \mathrm{n}=51$ chromosomes, showing distinct structures (a-c). The dashes indicate an apparent lacking of homologues.

Although we can offer no definite hypothesis for this chromosomal variation some preliminary considerations can be drawn which may be useful in directing further studies. We firstly suggest the occurrence of two putative karyotypic forms for the Prata river $H$. unitaeniatus specimens, an A-form karyotype represented by specimens with a $2 \mathrm{n}=52(44 \mathrm{M} / \mathrm{SM}+4 \mathrm{ST}+4 \mathrm{~A})$ karyotype, three pairs of NOR-bearing chromosomes and two pairs of $5 \mathrm{~S}$ rDNA-

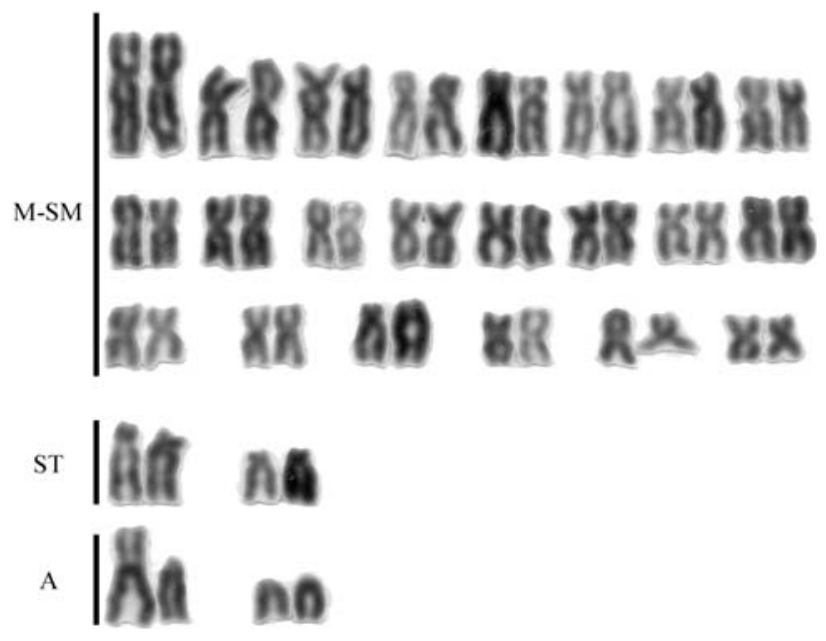

Figure 4 - Karyotype of Prata river Hoplerythrinus unitaeniatus with $2 \mathrm{n}=52$ chromosomes.

bearing chromosomes (Figures 4; 6h, i) and a B-form karyotype corresponding to the specimens with a $2 \mathrm{n}=50$ (46 M/SM + 4 A) karyotype, two pairs of NOR-bearing chromosomes and a single pair of 5S rDNA-bearing chromosomes (Figures 2a; 6b, c). We selected this B-form karyotype from those specimens with $2 \mathrm{n}=50$ chromosomes since it represents the homozygous condition for all chromosome pairs. Although both karyotypic forms are differentiated by their diploid number and the presence or absence of subtelocentric chromosomes they show similar chromosomes except for chromosome 4, which is a clearly submetacentric in the A-form but metacentric in the Bform. Assuming that such karyotypic forms could interbreed, the $2 n=51$ specimens would represent hybrid forms. Although the $2 \mathrm{n}=51$ karyotypes do not directly support this proposition since they diverge from the expected intermediary pattern concerning the parental karyotypes (Figures $3,6 e, f$ ), randomly additional crossings between the F1 specimens, or backcrossing between them and the putative parental forms, could have increased the chromosomal diversity in the population. Analysis of chromosomal frequency shows a dispersion around the modal values of $2 \mathrm{n}=50,2 \mathrm{n}=51$ and $2 \mathrm{n}=52$ chromosomes (Figure $1 \mathrm{~b}-\mathrm{d}$ ). Thus, it is possible that mitotic segregations leading to cells with 'balanced chromosomal combinations' (i.e., the most viable chromosomal arrays) would be favored. If so, the diploid numbers around the modal values would represent those cells bearing the less viable chromosomal combinations. In addition, the same process would explain the occurrence of distinct karyotypes with a same diploid number (i.e. $2 \mathrm{n}=50,2 \mathrm{n}=51$ and $2 \mathrm{n}=52$ ) which also represent favorable chromosomal arrangements.

The second hypothesis is related to the influence of environmental pollutants on chromosomal variability. Historical information shows that the Prata river area was a place of intense mineral extraction in which mercury was 


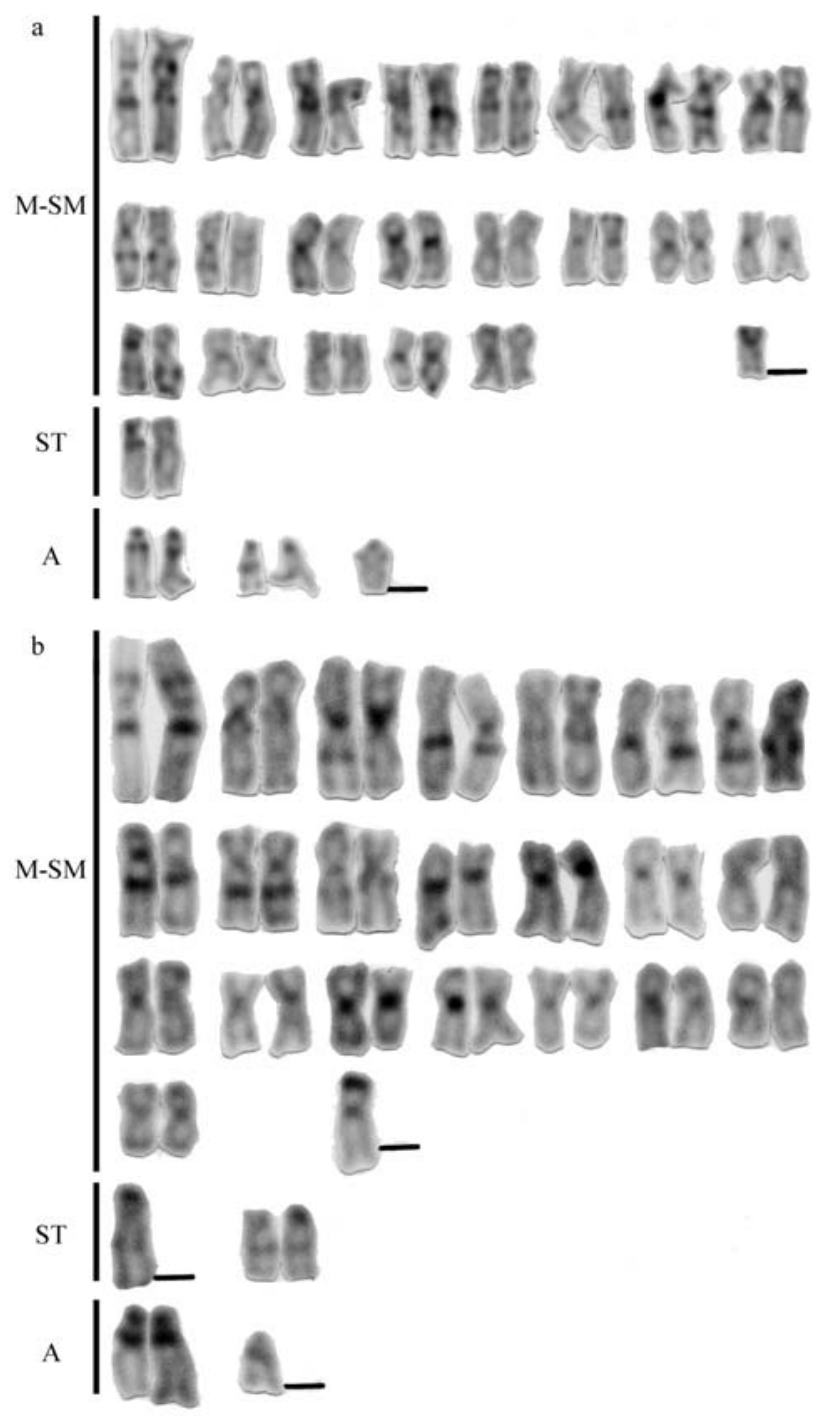

Figure 5 - The C-banding pattern of Prata river Hoplerythrinus unitaeniatus with (a) $2 n=50$ and (b) $2 n=51$ chromosomes, showing the similar distribution of the constitutive heterochromatin.
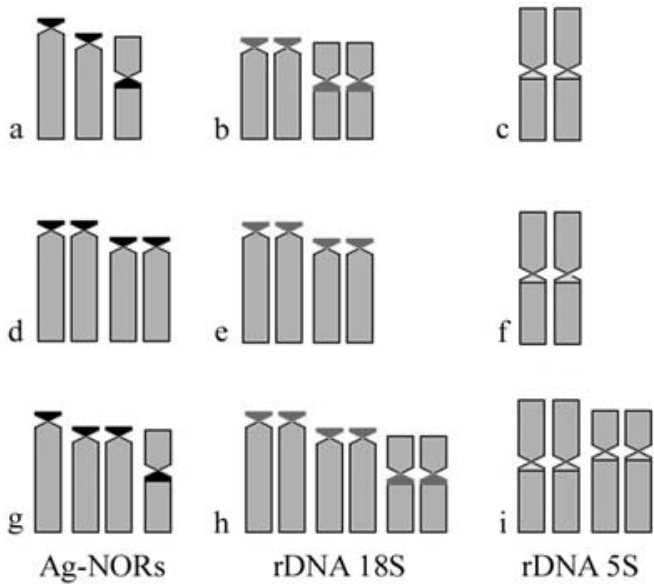

Figure 6 - Idiograms of Ag-NORs, 18S and 5S rDNA bearing chromosomes of Prata river Hoplerythrinus unitaeniatus. (a-c) specimens with $2 \mathrm{n}=50$ chromosomes; (d-f) specimens with $2 \mathrm{n}=51$ chromosomes; (g-i) specimens with $2 \mathrm{n}=52$ chromosomes. used for optimizing gold extraction. Although this activity is now restricted to an industrial level with more stringent pollution control, contaminants can persist within river sediments for a long time and since $H$. unitaeniatus is a typical carnivore fish on the top of the food chain there is a high chance of this fish accumulating toxic environmental pollutants. For instance it is known that sediments derived from mineral extraction in the Poconé region of the Brazilian state of Mato Grosso showed a level of mercury contamination 425 times higher than permissible levels, while mercury levels in fish from the Paraguay river have become extremely high (Sick, 1997).

In summary, our data shows that the Prata river $H$. unitaeniatus population shows a remarkable level of interand intra-individual chromosomal variability, which still lacks a conclusive explanation. We suggest that a comparative karyotypic analysis be conducted on specimens from the Prata river and other regional rivers and that a study be made of possible environmental and biological contamination caused by mineral extraction in order to provide a better understanding of the diversity of the Prata river $H$. unitaeniatus population.

\section{Acknowledgments}

The authors would like to thank Dr. Yoshimi Sato (CODEVASF, Três Marias, MG, Brazil) for his assistance in specimen collection. This work was performed with financial support provided by the Brazilian National Research Council (Conselho Nacional de Desenvolvimento Científico e Tecnológico, CNPq).

\section{References}

Beçak W, Beçak ML and Ohno S (1966) Intraindividual chromosomal polymorphism in green sunfish (Lepomis cyanellus) as evidence of somatic segregation. Cytogenetics 5:313320.

Bertollo LAC, Takahashi C and Moreira-Filho O (1978) Cytotaxonomic considerations on Hoplias lacerdae (Pisces, Erythrinidae). Brazil J Genet 1:103-120.

Diniz D and Bertollo LAC (2003) Karyotypic studies on Hoplerythrinus unitaeniatus (Pisces, Erythrinidae) populations. A biodiversity analysis. Caryologia 56:303-313.

Giles V, Thode G and Alvarez MC (1985) A new Robertsonian fusion in the multiple chromosome polymorphism of a Mediterranean population of Gobius paganellus (Gobiidae, Perciformes). Heredity 55:255-260.

Giuliano-Caetano L and Bertollo LAC (1988) Karyotype variability in Hoplerythrinus unitaeniatus (Pisces, Erythrinidae). I. Chromosome polymorphism in the rio Negro population (Manaus, State of Amazonas). Brazil J Genet 11:299-306.

Giuliano-Caetano L, Jorge LC, Moreira-Filho O and Bertollo LAC (2001) Comparative cytogenetics studies in Hoplerythrinus unitaeniatus populations. Cytologia 66:3943.

Hartley SE and Horne MT (1984) Chromosome polymorphism and constitutive heterochromatin in the Atlantic salmon, Salmo salar. Chromosoma 89:377-380. 
Hatanaka T and Galetti PM (2004) Mapping of the 18S and 5S ribosomal RNA genes in the fish Prochilodus argenteus Agassiz, 1929 (Characiformes, Prochilodontidae). Genetica 122:239-244.

Howell WM and Black DA (1980) Controlled silver-staining of nucleolus organizer regions with a protective colloidal developer: A 1-step method. Experientia 36:1014-1015.

Levan A, Fredga K and Sandberg AA (1964) Nomenclature for centromeric position on chromosomes. Hereditas 52:201220.

Martins C and Galetti PM (1999) Chromosomal location of 5S rDNA genes in Leporinus fish species (Anostomidae, Characiformes). Chrom Res 7:363-367.
Ohno S, Stenius C, Faisst E and Zenzes MT (1965) Post-zygotic chromosomal rearrangements in rainbow trout (Salmo irideus Gibbons). Cytogenetics 4:117-129.

Pinkel D, Straume T and Gray JW (1986) Cytogenetic analysis using quantitative, high-sensitivity, fluorescence hybridization. Proc Natl Acad Sci USA 83:2934-2938.

Sick H (1997) Ornitologia Brasileira, Uma Introdução. Nova Fronteira, Rio de Janeiro, 862 pp.

Sumner AT (1972) A simple technique for demonstrating centromeric heterochromatin. Exp Cell Res 75:304-305.

Thode G, Giles V and Alvarez MC (1985) Multiple chromosome polymorphism in Gobius paganellus (Teleostei, Perciformes). Heredity 54:3-7.

Associate Editor: Fausto Foresti 